Article

\title{
Suitability Analysis and Planning of Green Infrastructure in Montevideo, Uruguay
}

\author{
Agustina Apud ${ }^{1, *}$, Robert Faggian ${ }^{2}$, Victor Sposito ${ }^{2}$ and Diego Martino ${ }^{3}$ \\ 1 Faculty of Science, Engineering and Build Environment, Deakin University, Melbourne, VIC 3125, Australia \\ 2 Centre for Regional and Rural Futures, Faculty of Science, Engineering and Build Environment, \\ Deakin University, Melbourne, VIC 3125, Australia; r.faggian@deakin.edu.au (R.F.); \\ v.sposito@deakin.edu.au (V.S.) \\ 3 Facultad de Arquitectura, Universidad ORT Uruguay, 11100 Montevideo, Uruguay; \\ diegomartinouruguay@gmail.com \\ * Correspondence: ma.apud@gmail.com
}

Received: 26 September 2020; Accepted: 2 November 2020; Published: 20 November 2020

\begin{abstract}
Urban green infrastructure (UGI) has the potential to address a wide range of challenges associated with rapidly growing cities in a changing climate, while also providing multiple environmental, economic and social benefits. However, the location of projects is often determined according to a single potential benefit rather than a set of benefits. Furthermore, while UGI is recognized as a successful strategy to support resilience in many cities around the world, it has not been implemented in Uruguay. This study develops a model to identify priority areas in need of green infrastructure in Montevideo, Uruguay. The GIS-based model, termed the "Green Infrastructure Suitability Model" (GISM) is based on a multi-criteria decision analysis approach and is similar in structure to land suitability analysis. The model considers a range of socioeconomic, biophysical and environmental factors to prioritize the need for UGI across the case-study region. Resulting suitability maps identify areas for multifunctional UGI localization in places where benefits can be maximized. The GISM has potential as a tool to support future planning for multifunctional UGI.
\end{abstract}

Keywords: urban green infrastructure; urban planning; GIS modelling; suitability analysis

\section{Introduction}

Urban areas are confronting more social, economic and environmental pressures than in any other period of history [1,2]. Cities face challenges such as population growth, climate change, scarcity of resources, environmental degradation, contamination and increased hazards to human health $[1,3,4]$. The global urban area represents less than $3 \%$ of the total world surface [5]. However, cities consume around $60-80 \%$ of the world's energy and contribute to more than $70 \%$ of the total global $\mathrm{CO}_{2}$ emissions [1,6]. The current trajectory of expansion of our cities increases pressure on natural ecosystems and contributes to the loss of biodiversity, which is intensified by the impacts of climate change [7-9]. The future well-being of human populations is closely connected to urban areas and their resilience to climate change. According to IPCC, 2014, it is crucial to act in urban centers in order to achieve global climate change adaptation and to improve the quality of life of future generations [10]. In this context, a different approach is needed to guide the upcoming development of our cities $[4,11]$. There is increasing evidence of the benefits that nature provides for human environments [12-15]. The application of green infrastructure (GI) in urban planning provides the opportunity to design cities and urban areas as living systems that are more connected with nature, creating healthier, resilient and sustainable urban environments [16-19]. GI and its application in spatial planning is recognized as a successful strategy to support resilience in many cities around the world [18]. However, in Uruguay, 
the term "green infrastructure" is not explicitly mentioned in existing planning policies and regulations. Although there is a growing interest in the promotion of natured-based solutions and in the protection of natural resources, GI has not been implemented as an integrated approach in urban planning yet [20]. Nevertheless, initiatives such as "Montevideo Resiliente", a strategy from the Municipality of Montevideo (IM) in collaboration with 100 Resilient Cities (Rockefeller Foundation) [21], or "NAP Ciudades", a National Adaptation Plan for cities and infrastructure adaptation, which is a work from the Ministerio de Vivienda Ordenamiento Territorial y Medio Ambiente (MVOTMA) and the United Nations Development Programme (UNDP) financed by the Green Climate Fund, include the concept of GI. The formerly mentioned plan aims to develop actions to adapt the city to climate change and reduce its vulnerability by encouraging sustainable initiatives such as green infrastructure development [22].

Although there is no single definition of GI, it can be described as an interconnected network of natural, semi-natural and built green spaces, designed for multifunctional purposes. These purposes include supporting biodiversity, restoring natural ecosystems, improving human well-being and increasing the resilience of cities $[8,16,19,23]$. Additionally, it provides an increase in the ecosystem services available, supporting multiple social, environmental and economic benefits, and it contributes to the adaptation of urban areas towards the impacts of climate change [24]. GI benefits provided to populations differ depending on the location, proximity to the population or area with needs and in the uniqueness of the resource [16].

The term GI is used for different scales, from national or regional ecological networks, to urban green space networks and local projects for stormwater management [25]. Urban green infrastructure (UGI) is referred to its particular application in urban environments. Urban areas are characterized by strong interactions between social and ecological systems and face complex social and environmental challenges [26]. Social challenges include population growth, poverty, inequality and an increasing demand in the consumption of water, food, land and energy. Ecosystems support human well-being but at the same time, environmental challenges, such as climate change, loss of biodiversity, deforestation and air and water pollution, are exacerbated by social pressures. Because of the interconnectedness of social and ecological systems, addressing these challenges needs an approach that integrates the multiple interlinkages and dependencies between both systems [27]. UGI planning is particularly appropriate for cities, as it is centered on a holistic understanding of the relations between both systems [25].

UGI has the potential to forge new connections between the two systems, resulting in a more effective way to manage complexity than traditional planning does [25]. According to Hansen et al. 2017, UGI planning is based on core principles: multifunctionality, integration, connectivity and social inclusion; and supporting principles: multi-scale, multi-object and multi-disciplinary [24]. These principles can be combined in diverse ways to respond to particular challenges that different regions may face [24]. In addition, the flexibility and diversity of UGI components allow different combinations to be tailored for different local contexts, spatial levels and issues, resulting in a potential adaptation strategy for planning resilient urban areas $[16,17,25]$. UGI contributes to the adaptation of urban areas towards the impacts of climate change because of its capacity to: retain, store and reuse water later, reducing stormwater runoff and floods; increase permeable surfaces; regulate local temperature; improve water quality; increase buildings efficiency; and provide new habitats for species [8,28]. UGI is a potential tool to be used as an adaptation strategy for planning and designing resilient urban areas to combat the impacts of climate change [16,17].

International examples of UGI application, demonstrate how UGI can be successfully implemented in spatial planning to promote sustainable, resilient cities [29]. UGI reconnects cities with nature and turns them into a more resilient system with the possibility to tackle multiple urban challenges [30]. One of the core principles of UGI is the capacity to provide several benefits and to integrate different environmental, social and economic functions [31]. In many cities, the development of UGI projects is promoted due to their potential to address a wide range of urban challenges and at the same time provide multiple benefits and functions. However, the location of such projects is often determined according to only a single potential benefit (for example, stormwater management) [19,32]. 
In this context, the aim of the research is to develop a model to identify priority areas for green infrastructure in Montevideo. The best sites for UGI should be those where benefits are maximized and respond to various prioritized challenges or functions. In this way, the investment in UGI is justified, the role it plays is strengthened and its implementation can be promoted within the region. This study, therefore, analyses the application of UGI as a planning approach and develops a model to identify potential localizations for within the case-study city of Montevideo. The model allows planners to guide the future development of candidate areas, increase their resilience and improve the quality of life of their populations.

\section{Materials and Methods}

\subsection{Study Area}

Montevideo is the capital of Uruguay and its biggest urban area. It is located in the south of the country, on the north bank of the Rio de la Plata. It has an area of $530 \mathrm{~km}^{2}$ and a population of 1.319.108 inhabitants [33]. Although being the smallest municipal "department" of the country, it is the department with the greatest population-98.9 per cent of the population lives in the urban area. Furthermore, it is an important economic center, generating more than 50 per cent of the GDP of the country [34]. These characteristics make Montevideo's sustainable development important not only locally but also at a regional and national scale [34].

\subsubsection{Urban Expansion and Environmental Concerns}

The expansion of the urban area over rural land has been a constant in the region, even though population growth has been relatively stable or even had negative growth in the last years [34]. The economic crisis in the 1970s, 1980s and early 2000s contributed to the process of urban fragmentation, expelling population from consolidated urban areas to peripheral areas. As a result, degradation of some areas of the city and sub-utilization of existing urban infrastructure occurred [21]. The unplanned urban expansion exerts pressure on natural resources, resulting in environmental conflicts, contamination of watercourses, loss of biodiversity, deterioration of fragile ecosystems, degradation of productive soils and land use conflicts $[21,34]$.

The rural sector represents 62 per cent of the area of Montevideo and has a fundamental role in the sustainability of the region [34]. Montevideo Municipality aims to limit urban expansion and to transform the rural-urban interphase, which is considered a "strategic area" for the region, into an integrated transition zone with the rest of the city [35]. Shortages of infrastructures as well as lack of identity, integrity and connectivity with the rest of the city are some of the problems found in these areas [34].

\subsubsection{Climate Change in the Region}

Montevideo is a coastal city, which makes it especially vulnerable to some of the effects of climate change such as floods, storm surges or sea-level rise. According to Montevideo Resiliente, 2018, there are three main impacts affecting the region, these impacts are severe storms, strong winds, heavy rains, pluvial flooding and housing, trees and infrastructure collapse [34]. In addition, other impacts such as droughts, cold and heat waves, coastal floods, tornadoes, hail and frost are expected to increase [36].

Changes in rainfall patterns are already affecting the region. In the last decade, Uruguay has been affected by more frequent-severe floods and droughts. In the year 2015, as a consequence of floods, at least 20,000 people had to be evacuated from their houses in urban areas [22]. The analysis of historical precipitations for the last 30 years indicates a change in the annual rainfall and confirms a growing tendency in the annual precipitation values for the region [22].

The increase in quantity and intensity of precipitations will result in more severe floods and damages to housing, infrastructures, land and public services. These impacts especially affect areas close to watercourses and to vulnerable populations living in floodplains [34]. However, not only 
marginal areas are being affected; some central areas are already facing deficiencies in urban drainage systems and pluvial flooding during heavy rains. According to SEPS 2017, within Montevideo's consolidated urban area, there are areas affected by floods and the population living within these areas is estimated to be around 203,500 inhabitants [37].

The historical analysis of the annual mean temperature in Uruguay shows an increasing trend in the evolution of the mean temperature. It is projected that the temperature in Uruguay increases up to 2-3 Celsius degrees for the year 2100 [22]. The number of dry days will increase and this will lead to more frequent droughts and problems with water availability [34]. The expected increase in extreme weather events' frequency for the future must be considered in the planning of the city [38].

\subsection{Methodology}

For this study, a GIS-based methodology, "Green Infrastructure Suitability Model" (GISM), is developed with the purpose to identify priority areas in need of green infrastructure localization in Montevideo. The GISM is based on land suitability analysis (LSA) methodology. LSA focus on the process of determining the most and the least appropriate area for the location of a specified purpose such as a future land use [39]. To identify the best locations for UGI, several criteria need to be considered simultaneously. As such, this research integrated a Multi-Criteria Evaluation (MCE) method with a Geographic Information System (GIS). MCE is useful because it allows the consideration of a number of alternatives (or choice possibilities) in light of multiple objectives (or criteria) and conflicting preferences (or priorities) [40,41].

MCE has been used extensively for land suitability modelling where it is primarily concerned with how to combine different information (data layers) from several criteria to form a single index of evaluation [42-45]. LSA considers the landscape as the result of complex interactions among the social, economic and environmental fields [46]. It aims to improve natural resource management while obtaining the most benefits possible from each of the other fields, in order that the main natural elements, physical and biological process, as well as the social and cultural values of the community, are considered [46,47].

Suitability methodologies generally involve six main steps, which include: identifying site issues and goals, finding existing sources and available data; establishing a criteria (or appropriate factors to be evaluated); ranking and weighing the criteria, analyzing the data with geographic information systems (GIS); and evaluating outputs and results.

The methodology developed (see Figure 1) is based on the selection and combination of different factors to evaluate and analyze the region through the integration of different layers of spatial data with the purpose to create a single evaluation index. The model aims to detect spatial priorities for the location of GI considering certain specific issues that the region is facing and that need to be addressed. Priority areas for GI localization need to be located in places where benefits are maximized so that the role and value of green infrastructure in the region are strengthened. The model will determine the most suitable areas in need of GI localization.

The first step of the methodology, "Study area" includes the revision of the existing bibliography, plans and policies and consultation with pubic organization and experts with the objective to identify the region's context, challenges, objectives and goals that the region has and that can be addressed through the implementation of GI. In addition, the main socio-ecological elements of the area are identified; this includes existing green areas and biodiversity values, water system, cultural system and key infrastructures. 


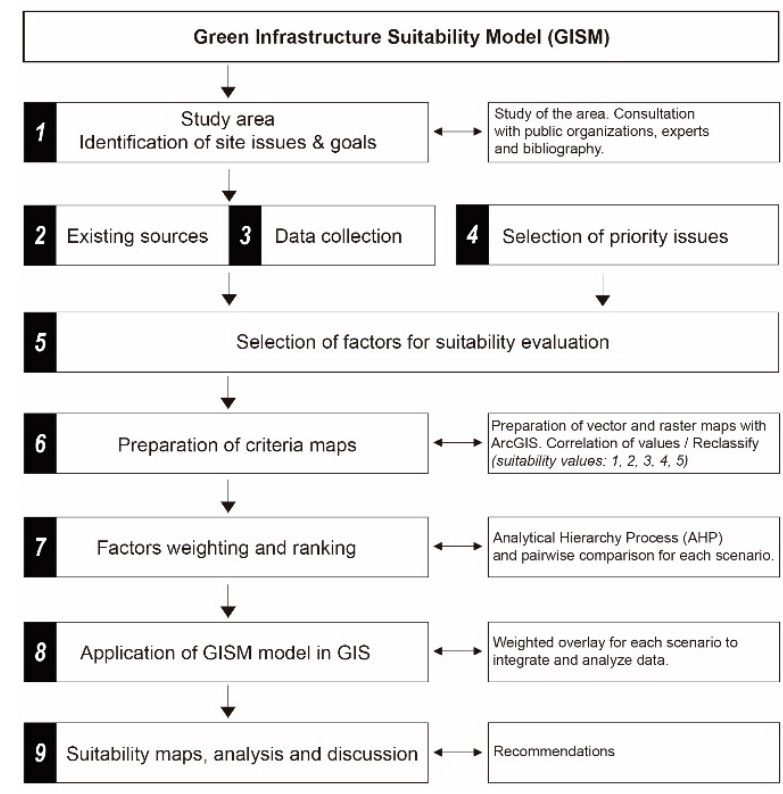

(a)

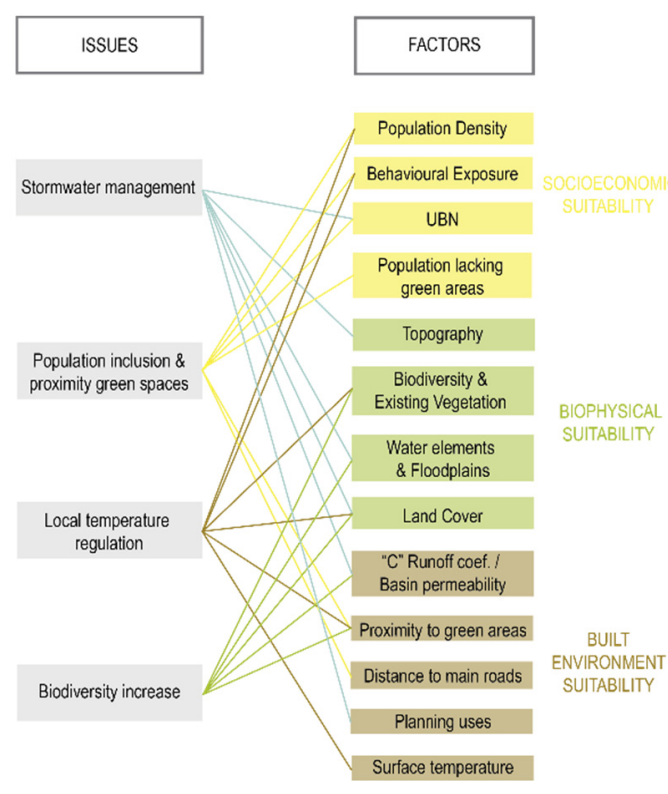

(b)

Figure 1. (a) Green infrastructure suitability model (GISM); (b) Correlation between selected factors and their influence on the region's priority issues.

\subsubsection{Selection of Priority Issues}

Taking into account the context, the current situation of the region, and existing initiatives and priorities established by the municipality of Montevideo, four main priority issues are selected to be addressed with the implementation of GI. The selected issues will serve as priorities to weigh and evaluate individual factors. The priority issues selected are stormwater management; local temperature regulation; population inclusion and proximity to public green spaces; and increase of biodiversity.

\subsubsection{Selection of Factors for Suitability Evaluation}

The selection of factors is based on a literature review which takes into account different international studies on the topic, which have looked on methodologies for GI localization based on GIS modelling. From this search, a table with a list of factors was developed. This table includes the most common factors that appeared among the different studies. The cases selected as references provide guidance for this research, advice on the criteria to consider and the rank and the weights, as long as they deal with a comparable purpose. A second revision of the factors was conducted according to the region's context and data availability.

Main socio-economic, biophysical and built environment aspects were considered to determine selected factors. Socioeconomic factors were selected considering that GI development is encouraged in areas with high population density and great behavioral exposure. Behavioral exposure refers to areas where high concentrations of active people are exposed, such as main economic, commercial and social centers [48]. GI provides more benefits when it is located close to people and to the areas in need [16]. Another important factor to consider is the areas where population with the lowest socioeconomic levels is located. These areas need to be prioritized as they represent sectors with fewer possibilities of accessibility [3].

Main biophysical elements are essential components and were recognized to ensure that existing natural values and processes of the region are protected [46]. Factors such as topography, existing water elements, floodplains, vegetation, biodiversity and land cover were considered. Finally, some factors to represent the built environment were selected so that existing built infrastructure can be used more efficiently and its interaction with its rural and natural surrounding is enhanced [34]. 
Each factor has a different weight in the model. Weights may vary according to the priority issue that is being considered. The factors selected are population density, behavioral exposure, population with unsatisfied basic needs (UBN), population lacking access to green areas, topography (considers land slope, elevation and flow accumulation), biodiversity and existing vegetation, water elements and floodplains, land cover, basin permeability, proximity to green areas, distance to main roads, planning uses and surface temperature.

\subsubsection{Preparation of Criteria Maps}

Each of the individual factors selected is mapped and its values are reclassified (see Figure 2). For the reclassification, its values are correlated to a range or suitability rank, which is graded from 1 to 5 , in a new data layer. Each cell of the factors' maps contains a suitability value, where the least suitable values for a specific objective are represented with one, while the most suitable values are indicated with five. The suitability rank may change according to the priority that is being evaluated.
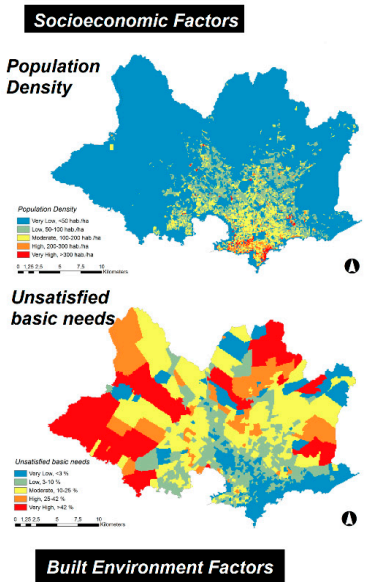

Built Environment Factors

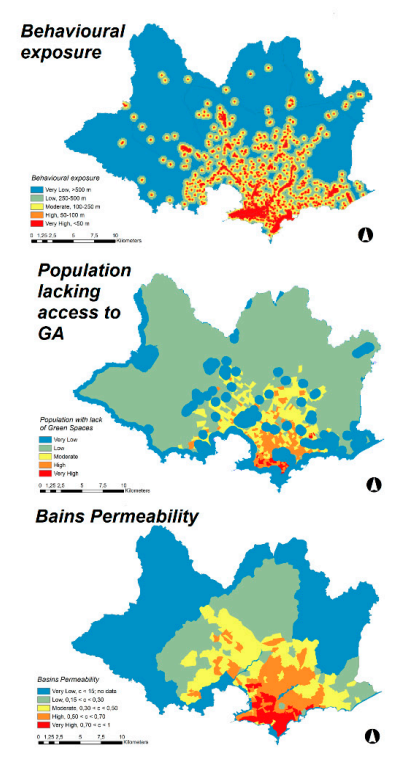

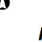

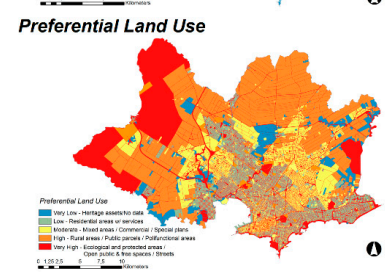

Figure 2. Individual factors or criteria maps.

\subsubsection{Factors Weighting and Ranking}

The Analytical Hierarchy Process (AHP) is based on expert knowledge and it is used in LSA to determine weighting scores. This process is a multi-criteria decision-making approach, suitable to deal with complex decisions [49]. AHP breaks the "problem" down into different factors or components and organizes them into a hierarchy. The hierarchy is organized in the form of a decision tree, with the main objective at the top and the second and tertiary criteria below. Priorities are assigned to the different elements by allocating them a number or value, which represent the different degree of importance of the elements involved in the hierarchy [49].

As explained by Saaty (1995), "basically the AHP is a method of breaking down a complex unstructured situation into its component parts; arranging these parts, or variables, into a hierarchical order [or decision tree]; assigning numerical values to subjective judgments on the relative importance of each variable; and synthesizing the judgments to determine which variables have the highest 
priority and should be acted upon to influence the outcome of the situation. AHP incorporates both the qualitative and the quantitative aspects of human thought: the qualitative to define the problem and its hierarchy and the quantitative to express judgments and preferences concisely. The process itself is designed to integrate these dual properties" [50]. When AHP is integrated with GIS, it can deal with criteria that are interdependent, both from the effect on (urban) land and in the interaction between spatial units [51].

For this study, for the assignation of weights to each factor, a pair-wise comparison matrix was used to determine the different weights. This pair-wise comparison matrix is an AHP Excel Template with Multiple Inputs [52], which includes the calculation of a consistency ratio, to evaluate the consistency of the different pairwise comparison. Based on the four priorities selected (stormwater management; local temperature regulation; population inclusion and proximity to public green spaces; and increase in biodiversity), the diverse factors selected are weighted differently according to their influence on the issue considered. The weighting process was done based on the literature review as well as on other similar case studies selected as a reference. In this process, each element is compared with the rest of the others. The most important element has to be defined over the other. A value number has to be assigned to determine how much important is one factor over the other. The pairwise comparison matrix calculates the weights that then are applied to the model $[49,52]$.

\subsubsection{Application of Green Infrastructure Suitability Model (GISM) in GIS}

The GISM model is elaborated using ArcMap 10.5.1 (Environmental Systems Research Institute (ESRI), Redlands, CA, USA), Model Builder [53], the criteria maps and the weights determined in the AHP for each priority issue, according to the diagram (see Figure 3). The different factors are combined with the rest of the others using weighted overlay analysis tool from ArcMap. The different factors are combined to create a single composite suitability map. This process is repeated for each priority issue (see Figure 4). Different weights are assigned to the factors according to its influence on each priority. As a result, four different suitability maps are obtained according to the four priorities considered.

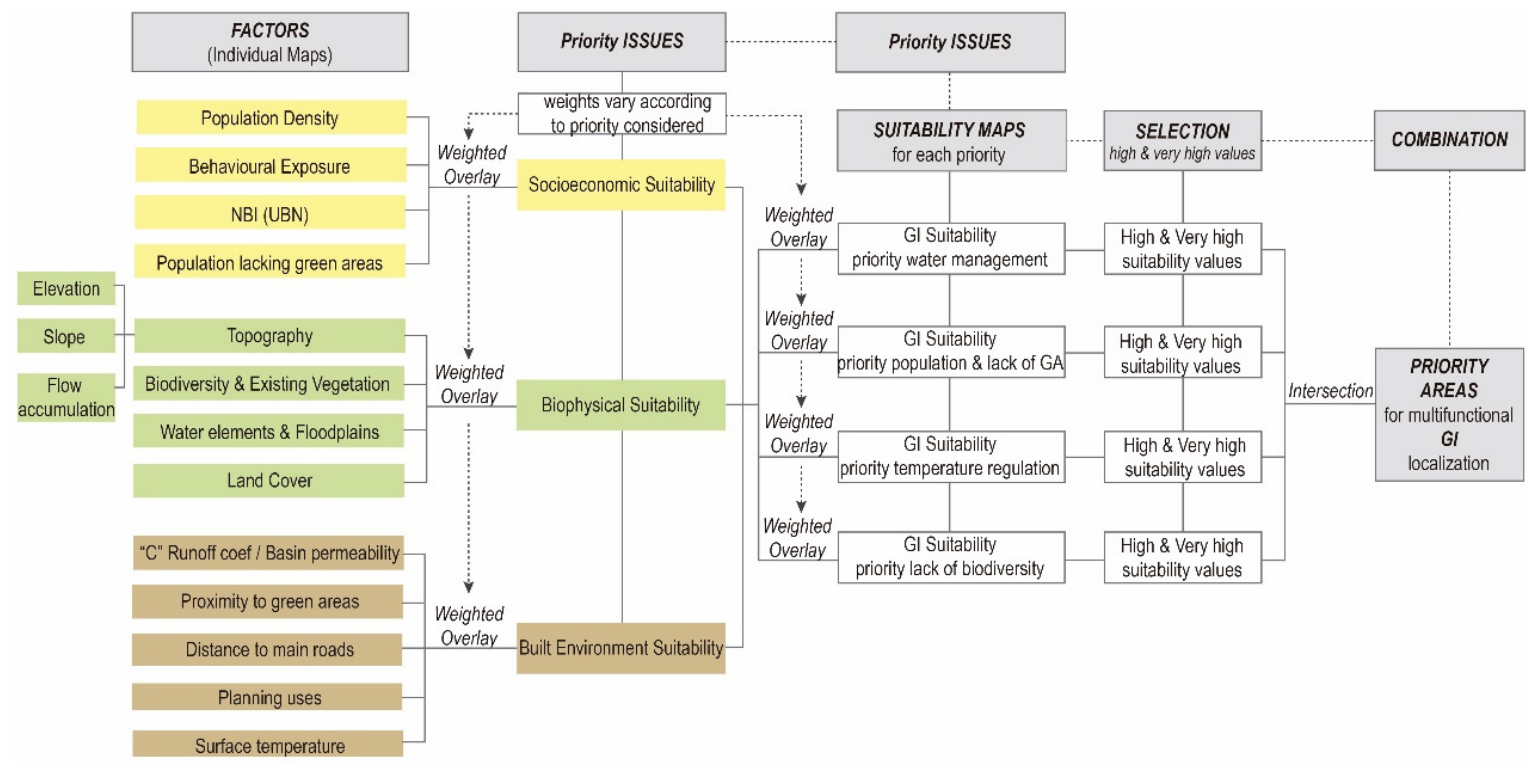

Figure 3. GISM ArcMap procedure. 

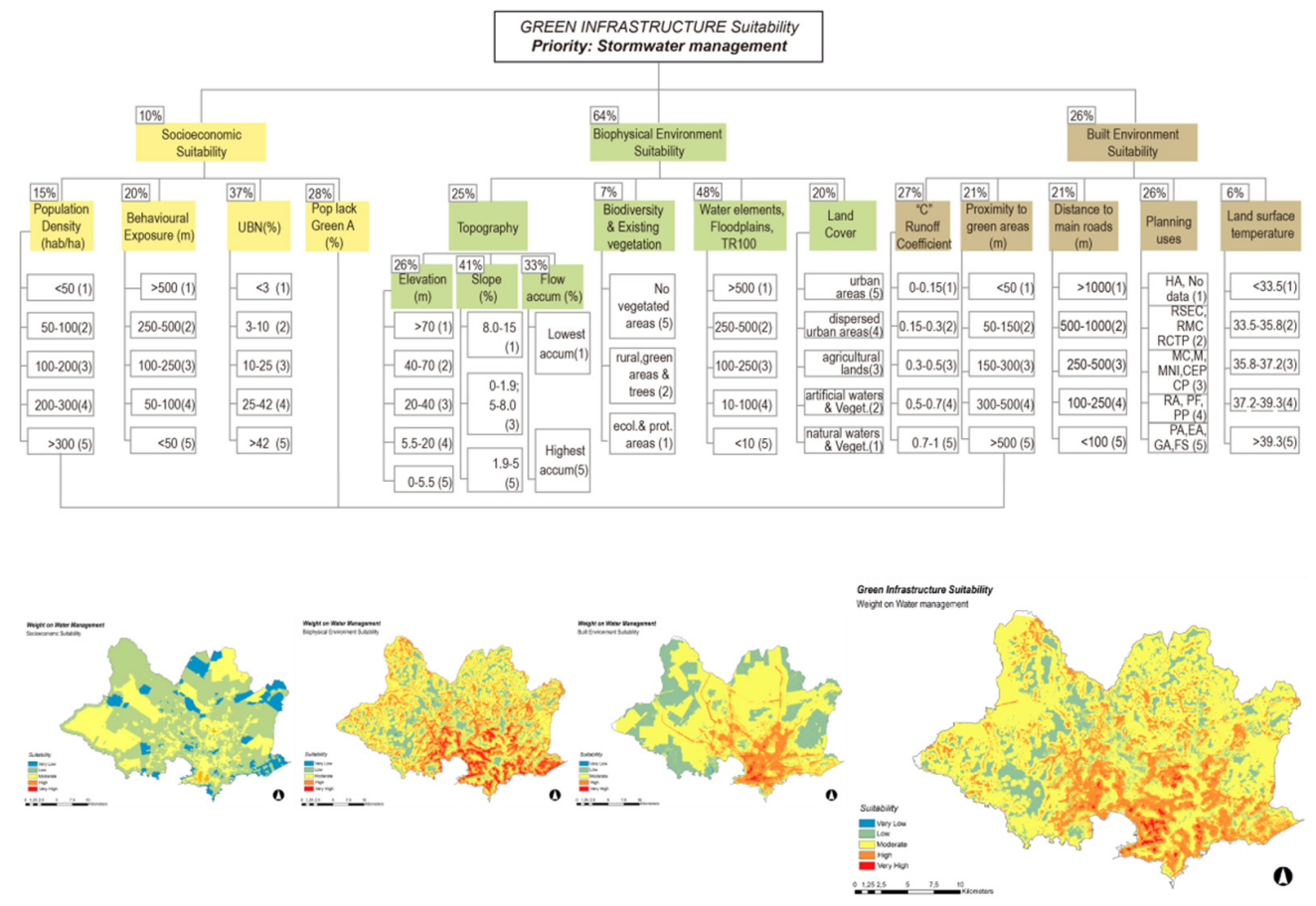

(a)

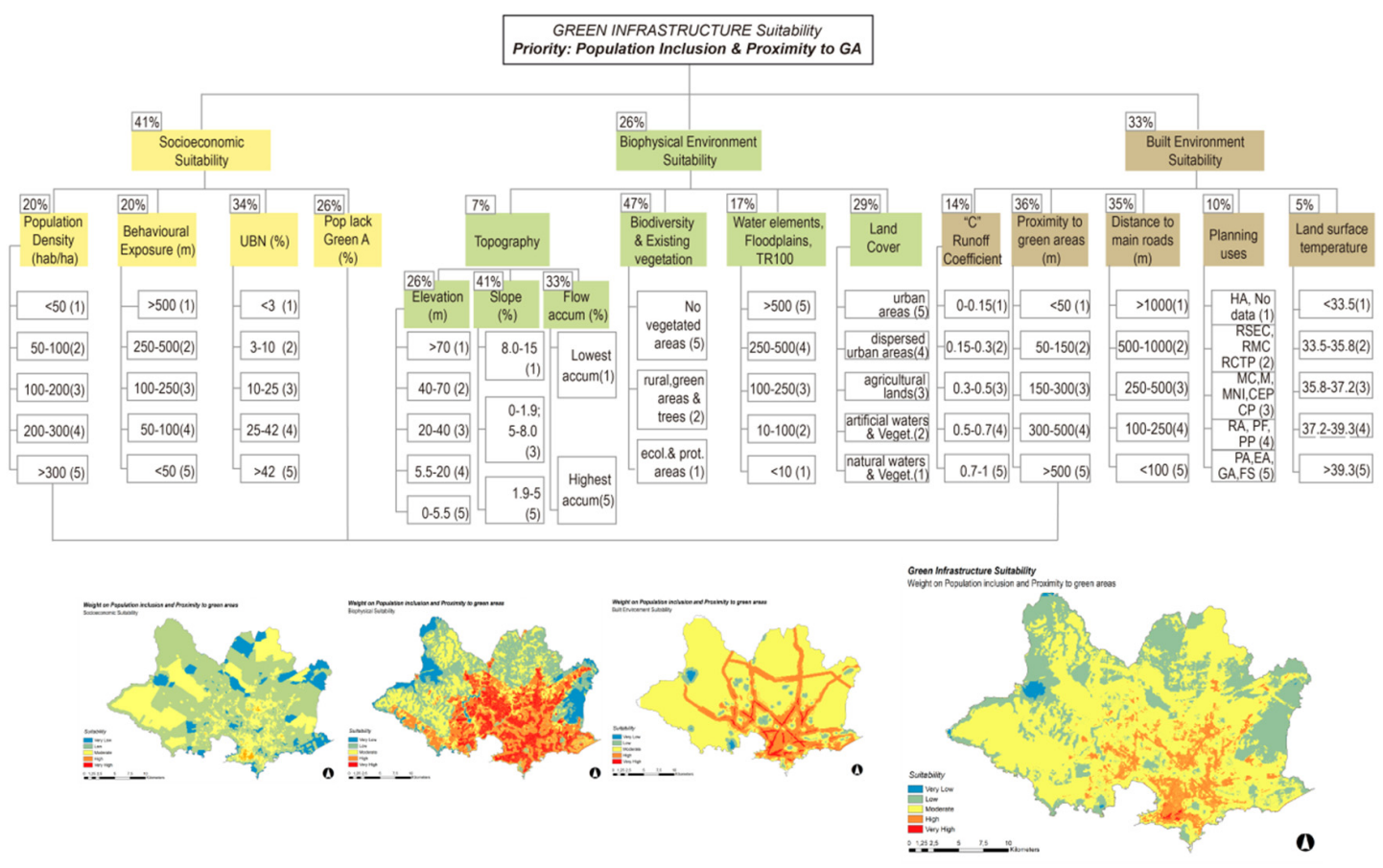

(b)

Figure 4. Cont. 


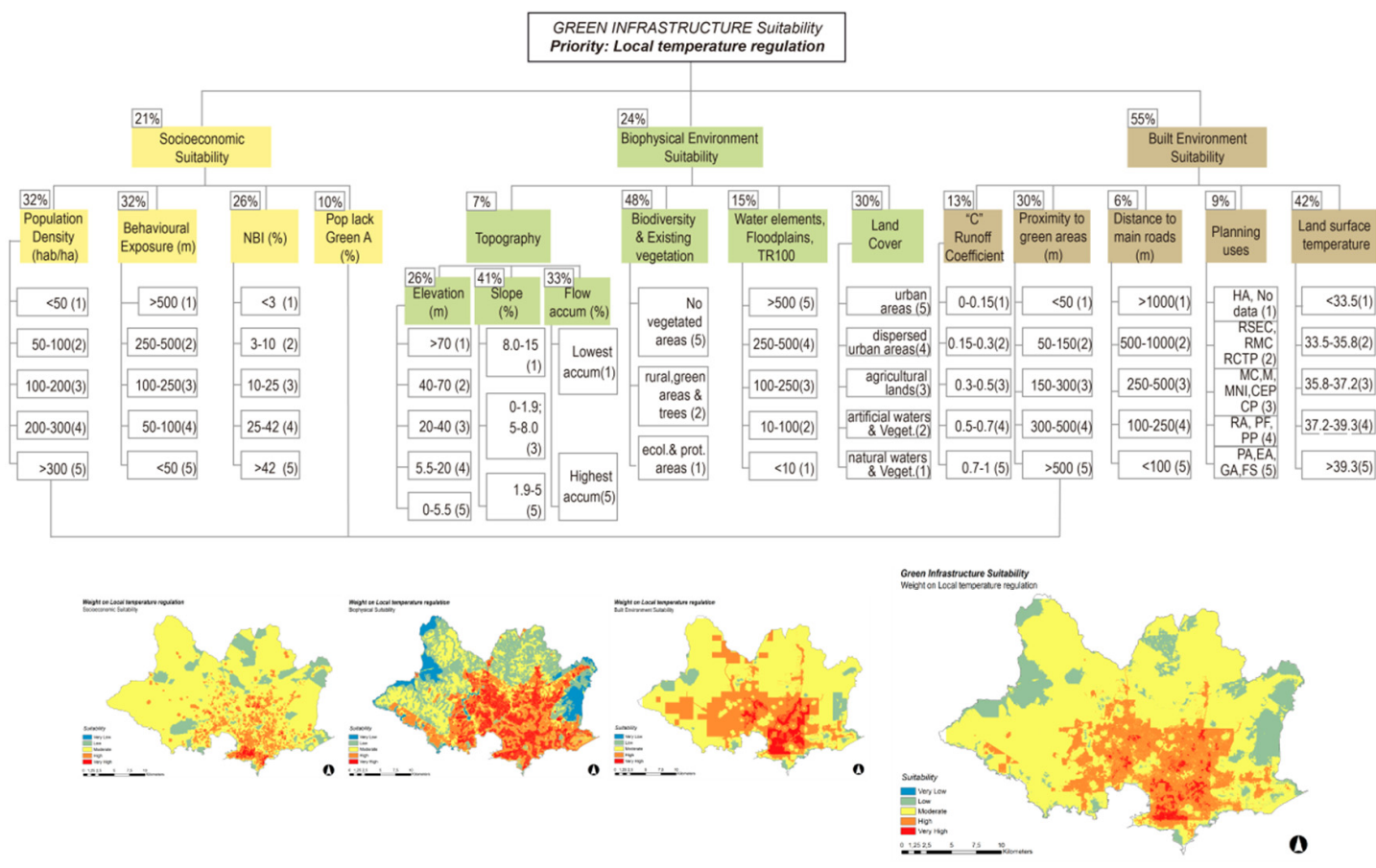

(c)

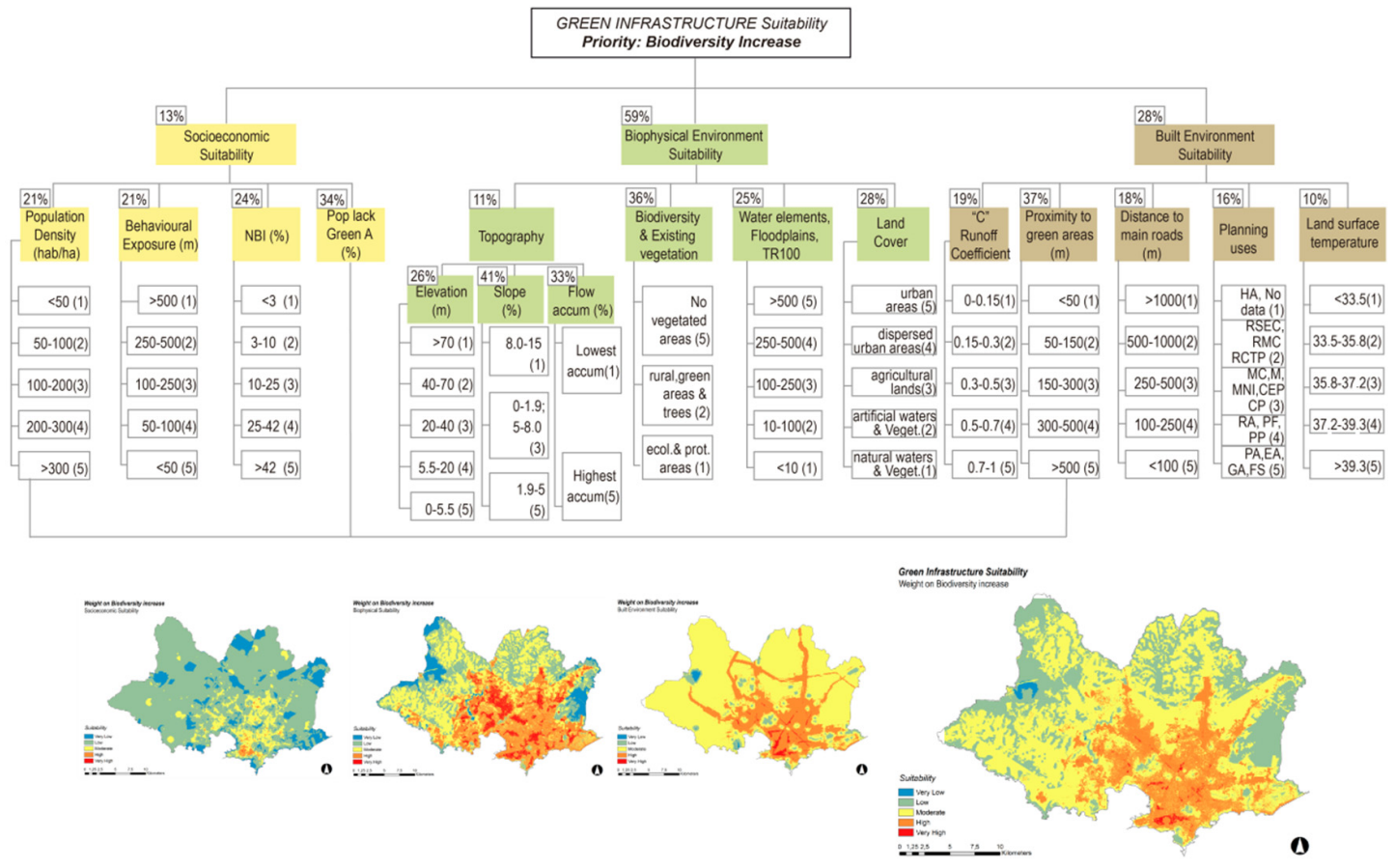

(d)

Figure 4. Analytical Hierarchy Process (AHP) and suitability maps for Montevideo GISM: (a) priority on water management. (b) Priority on population inclusion and proximity to green areas. (c) Priority on local temperature regulation. (d) Priority on biodiversity increase. 


\section{Results}

The GISM aims to identify priority areas in which to focus the development of Green Infrastructure (GI). The model is conceived as a first approach to the issue and as a primary stage in the identification of geographical locations in need of green areas. After this first analysis, and previous to GI implementation, a deeper examination at the local or neighborhood level should follow.

The results exposed show priority areas for GI localization in Montevideo; each suitability map (see Figure 5) shows suitable areas in need of GI localization responding to one of the priority issues selected. Suitability values range from very low to very high suitability. The areas in blue represent the lowest suitability values, while the red ones represent the areas with very high need of GI.

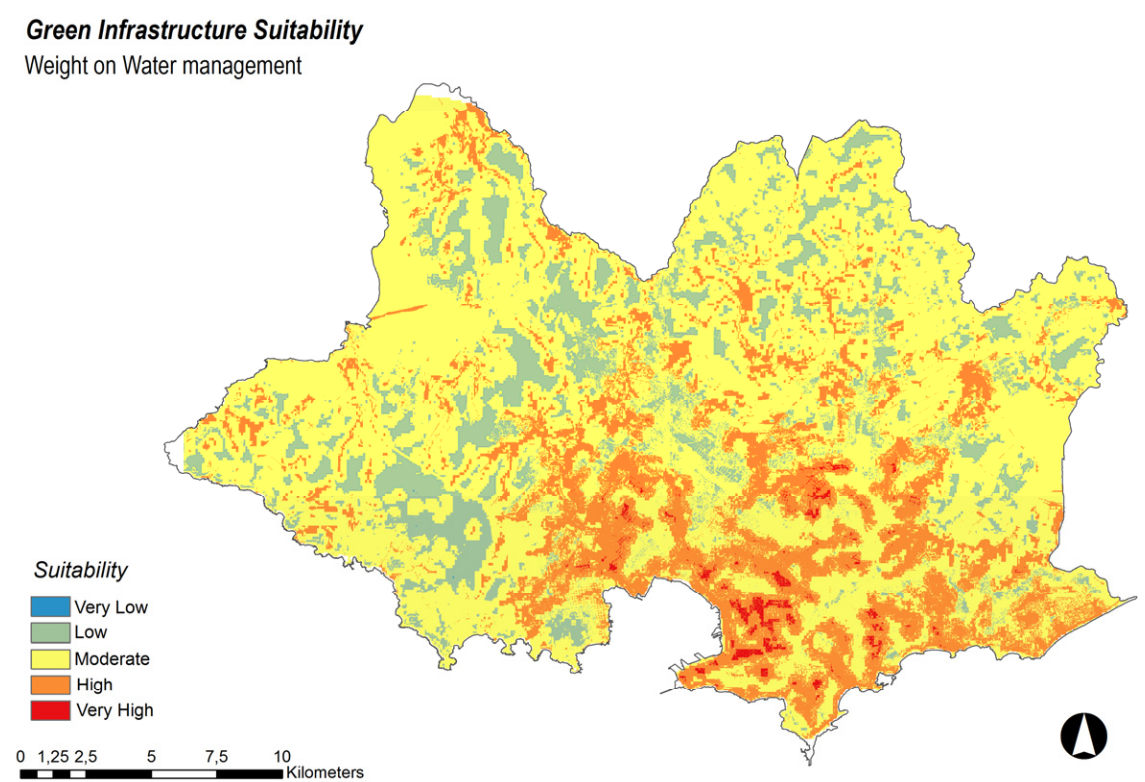

(a)

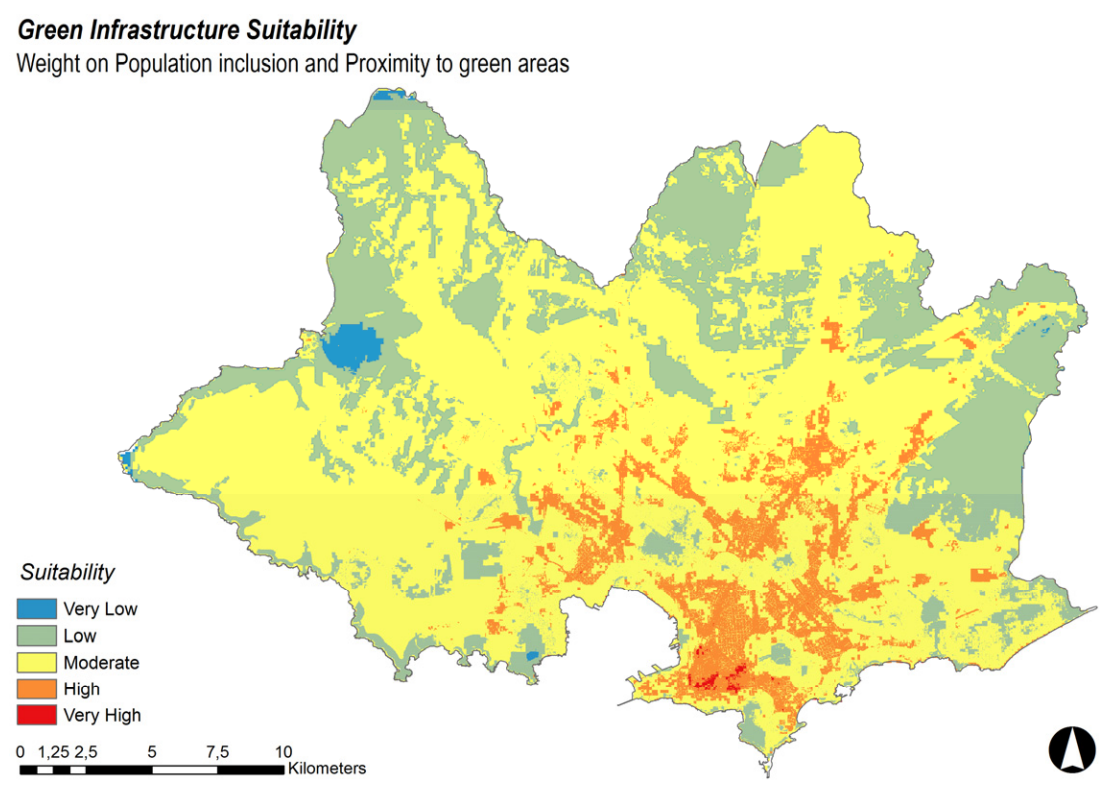

(b)

Figure 5. Cont. 
Green Infrastructure Suitability

Weight on Local temperature regulation

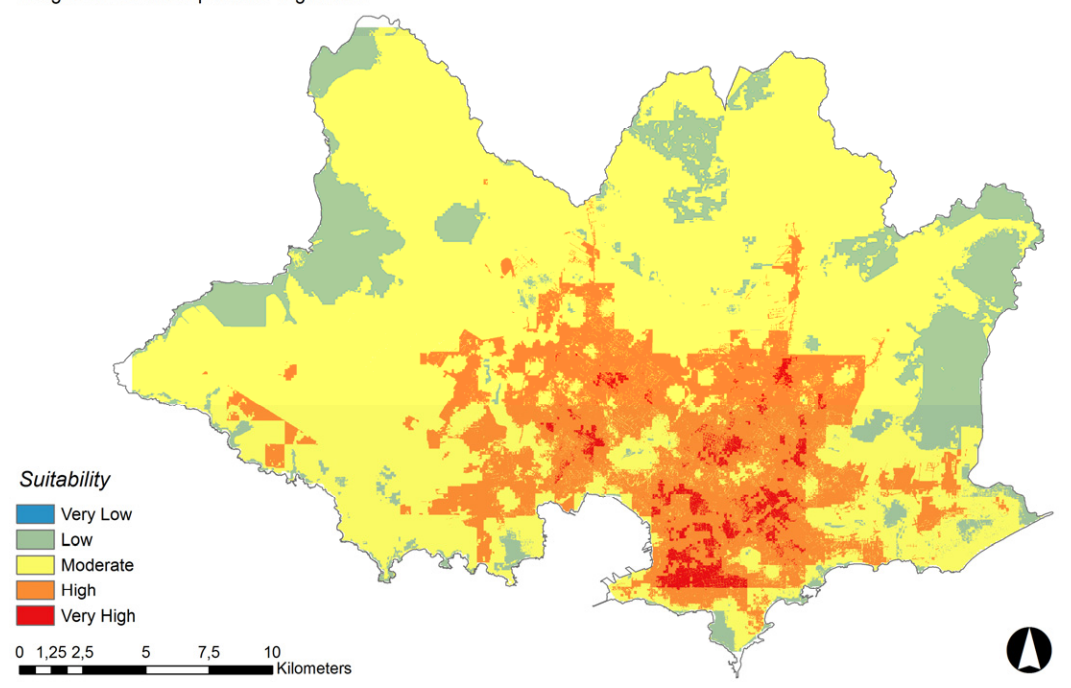

(c)

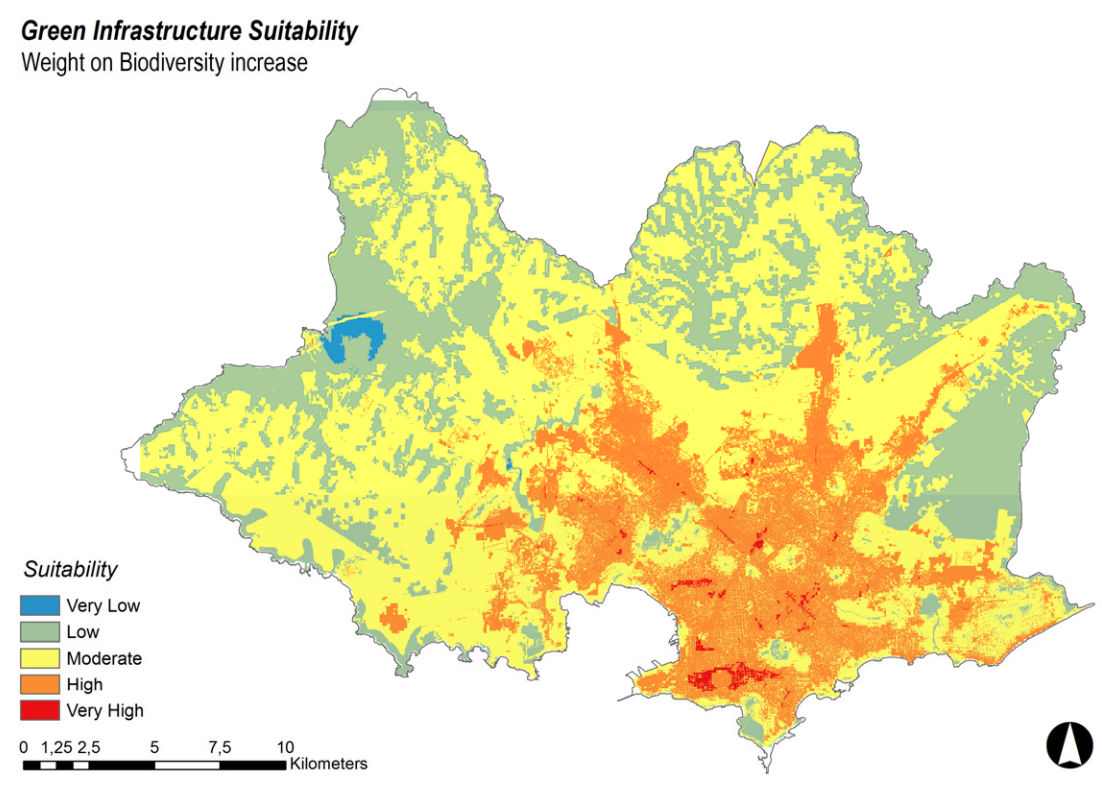

(d)

Figure 5. Green Infrastructure (GI) Suitability maps. (a) Map with weight on water management. (b) Map with weight on population inclusion and proximity to green areas. (c) Map with weight on local temperature regulation. (d) Map with weight on biodiversity increase.

\subsection{Priority: Stormwater Management}

High suitability values are associated with the presence of water elements, floodplains and natural drainage lines, which also correspond to the lowest topographic areas. This is related to the fact that these factors are assigned with the greatest weight among all the factors. Very high suitability values for GI localization can be seen in areas that correspond to two of the main watercourses and larger basins of the region. They are considered vulnerable areas affected by the increase in the intensity and frequency of precipitations related to climate change, whose impacts rise as a consequence of informal urban developments located in floodplain areas. Other sectors with a great concentration of high suitability values correspond to central areas of the city. Parts of these areas have been affected in some recent occasions when intense precipitation exceeded the urban drainage systems, resulting 
in severe urban floods. Furthermore, other sectors with high suitable values can be appreciated in areas that can be related to the location of former watercourses, which were channeled and remain under paved surfaces. As a consequence, when heavy rains happen, sewerage systems overflow, in the lowest points of the natural drainage lines water tends to pond and floods appear.

\subsection{Priority: Population Inclusion and Proximity to Green Areas}

High suitability areas for GI localization are concentrated within central sectors. This responds to the fact that the highest weight is assigned to the socioeconomic factors, in particular to populations lacking green areas and to populations with unsatisfied basic needs (UBN). High suitability values are distributed along the region, mainly concentrated in areas with populations lacking green areas and along main transport corridors. Changes in the weights assigned to individual factors modify the final suitability maps. Therefore, it is very important to define in advance the priorities to be addressed. For example, when a highest weight is assigned to UBN, high suitability values tend to decrease in central areas and increase in peripheral areas. On the contrary, as weight for population density and behavioral exposure are increased, central areas increase its suitability while peripheral areas decrease. Another tendency we can see is the maintenance of high suitability values along the main transport corridors.

\subsection{Priority: Local Temperature Regulation}

High suitability values for priority GI location for urban heat regulation correspond mainly to the areas currently defined as urban areas. Especially, they match to those areas with higher percentages of paved surfaces, greatest behavioral exposure and with less vegetation or fewer water elements. As suitability maps indicate, suitability values decrease in the presence of large green areas, main watercourses or close to the south, where temperature is influenced by the coast.

\subsection{Priority: Biodiversity Increase}

Most of the urban area is indicated as high suitability areas. There are some exceptions with lower suitability values within the urban area, which correspond to sectors where large green areas or watercourses are located. The suitability map obtained for this priority has numerous similarities with the map achieved for local temperature regulation priority. These results support the idea that the presence of green areas within urban areas has a great influence on the regulation of local temperature. Low suitability values mostly correspond to areas with existing biodiversity values. The reason for this is that the model prioritizes areas in need of natural areas. Consequently, areas with less or no existing vegetation are the highest weighted, whilst areas with existing vegetation are assigned with lower values. Nevertheless, this does not mean that areas rated as low and very low suitability values are not suitable for GI. On the contrary, existing biodiversity and natural elements in the whole region must be protected and enhanced.

Variations in the reclassification values of the biophysical factors result in different outcomes. For example, when considering the lack of vegetation as a priority issue, highest weights are assigned to areas lacking vegetation and biodiversity; on the contrary, highest weights are assigned to vegetation and ecological areas when considering the presence of high biodiversity values to protect and landscape connectivity. GI multifunctionality cannot always be successful at achieving all the benefits at the same time. Sometimes priority issues have no compatible locations. In these cases is important that stakeholders have clear objectives and evaluate different possibilities to make trade-offs when possible [32]. Different areas within the region show different suitability values according to the priority that is evaluated. The four suitability maps shown in Figure 5 provide a visualization of the least and the most suitable areas for GI implementation in the locations where GI is needed the most in Montevideo. 


\subsection{Selection of High and Very High Suitability Values}

High and very high suitability values from each case are selected with the purpose to compare commonalities among the different priorities (see Figure 6a). In addition, this allows for assessing the possibility of multifunctional GI localization in places that can be benefited the most. After high and very high suitability values for each priority are determined, they are intersected in a final suitability map using the overlay analysis tool from ArcMap 10.5.1 [53]. This tool allows us to intersect the common values and to perform an overlay analysis (see Figure $6 \mathrm{~b}$ ). The resulting map shows priority areas for localization of multifunctional GI.
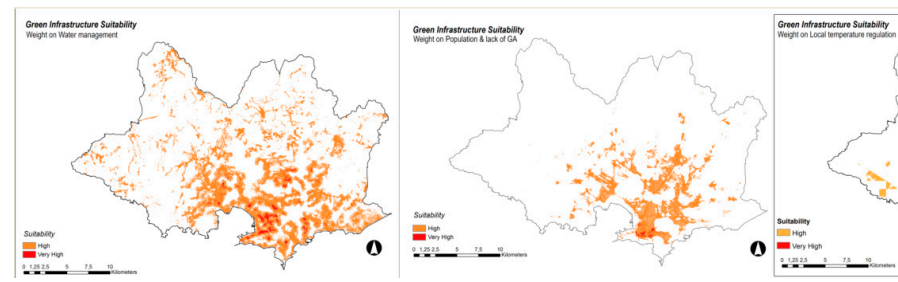

(a)

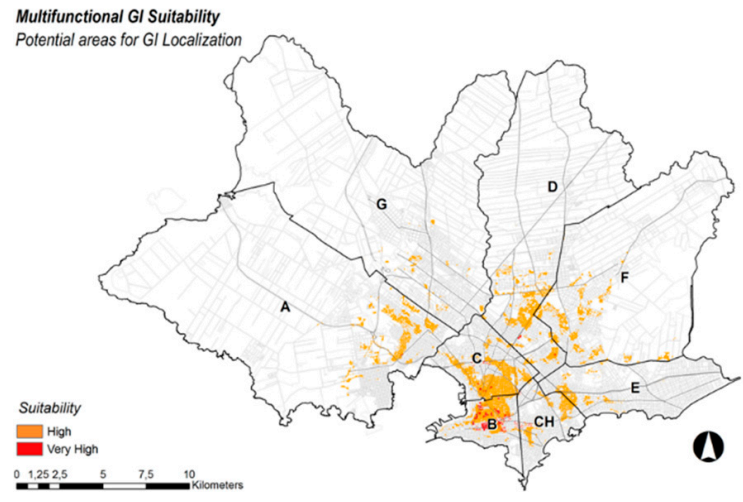

(b)

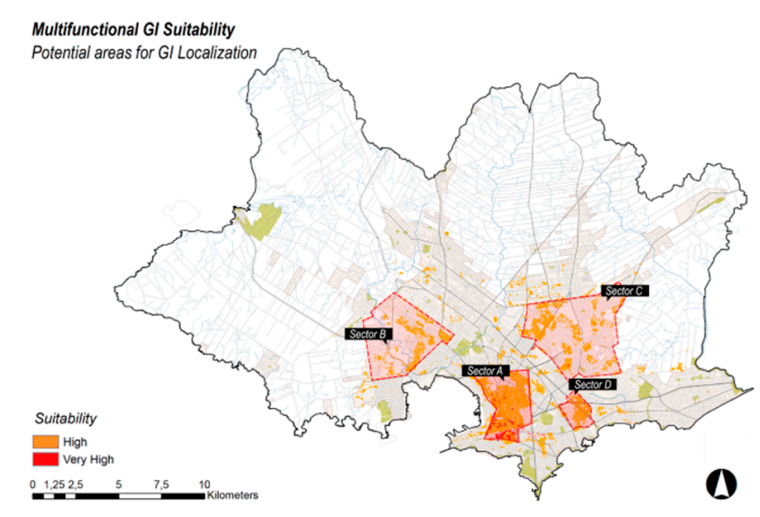

(c)

Figure 6. (a) High and very high suitability values for each priority issue; (b) intersection of high and very high suitability values of the four different cases for localization of multifunctional GI; (c) four major priority sectors for priority GI localization.

According to the resulting maps and the different high and very high suitability values obtained, four major areas or sectors are identified. Each sector is grouped because of proximity and similarities in its characteristics (see Figure 6c). These four sectors are: sector A (a central consolidated urban area), sector B (a complex area due to the coexistence of different land uses, such as rural production, industrial areas, consolidated urban areas and informal non-consolidated urban areas, particularly located in floodable areas. The presence of the Pantonoso basin contains significant ecological areas. However, these areas are affected by environmental damage, water and soil contamination, social vulnerability and the presence of precarious housing), sector $C$ (an area that involves urban areas and urban-rural interface, with different land-uses, unconsolidated areas, precarious habitats and loss of environmental services) and sector D (a small neighborhood sector, located in the coastal consolidated urban area). The results obtained and the former sectors described, need to be validated with the current situation and analyzed at a deeper level directly in the field.

\section{Discussion}

The model was able to identify a number of areas within the case-study region that are suitable locations for the implementation of GI. The GISM model considers different socioeconomic, biophysical and environmental factors to assess the different areas within the region. Additionally, it considers the 
diverse priority issues to be addressed. As a result, spatially significant areas in need of GI localization were detected.

For example, according to the model results, sector A (see Figure 6c) concentrates the most quantity of high and very high suitable values, therefore represents a clear area to start with the prioritization of GI localization. In fact, this is an important central urban area that functions as a centrality for the region. It is characterized because of the concentration of different social services and economic activities. In previous decades, the area suffered a process of abandonment and degradation. Nowadays, governmental plans aim to promote the recuperation of the area, of its infrastructure, services and environmental qualities, as well as to increase its population density, and reinforce its function as a centrality. GI implementation in this area can contribute to the government plans for recovering the role of the area and improve existing open public space, green areas and environmental qualities. In addition, it can help address issues such as stormwater management, lack of green space, local temperature regulation and increase of biodiversity.

The dominant urban morphology of buildings in sector A is considerably dense and closed with an intense occupation of the land with little green cover and large percentage of impervious surfaces. Areas such as existing green spaces, free open spaces, streets, public parcels and buildings, can be suitable for GI implementation. Existing open spaces in the area currently lack natural features; they are not able to provide any green or nature interactions as are mainly covered with impermeable surfaces and have little to no vegetation and the majority of existing vegetation are non-native species. In addition, they are generally designed as monofunctional spaces. Allowing more functions to happen can result in more benefits for the population.

Within the area, there are no large free spaces left for easy implementation of new green areas. Streets can be an opportunity to reintroduce ecological functions back into the built environment, as most of the streets in the sector are automobile-oriented, with large percentages of impervious surface cover. Existing open spaces represent a real possibility to easily increase the quantity and quality of nature in the area too. Public parcels and buildings represent another opportunity to find partner organizations for the implementation of GI. GI could be used by these organizations as opportunities to incorporate educational uses, recreational activities or ecological purposes, such as urban gardens for the community. Vacant parcels and abandoned buildings have high chances to provide available space for temporary or permanent use for the localization of GI. With the incorporation of GI, the area can improve its environment, increase its land value and increase the quality of life of its population.

If we consider sector B (see Figure 6c) as another example, we notice that it is a very different sector to sector A. However, GI implementation in this area can be as important as in sector A. Sector $B$ involves part of the Pantanoso basin, which is characterized by high social vulnerability, informal settlements and environmental degradation. Currently, there are existing municipality plans for this sector that aim to recover the area. GI implementation in this sector can help to promote the protection of existing natural areas and landscapes with high biodiversity values, which are contiguous to urban areas and threatened by urban activities. These areas need to be managed to incorporate different functions, such as land conservation, stormwater management and recreational uses. Particularly, natural areas such as riparian areas and wetlands should be prioritized for conservation, creating stream buffers and areas for native nature regeneration as well as stormwater parks.

The main purpose of this research, to develop a model to identify priority areas for GI in Montevideo, was accomplished and importantly it is a generally applicable model that could be used in any city. The parameters within the model are not specific to Montevideo and the model does not require detailed or rare data; therefore, we expect that it could be deployed anywhere in the world. The methodology developed has potential as a tool to support future planning for multifunctional green infrastructure (GI) and to assist policymakers in making the most appropriate choice to locate GI projects in places where benefits can be maximized.

One of the core components of suitability analysis is the generation of suitability maps. Suitability maps were generated according to different priorities. These maps show the least and most suitable 
areas in need of green infrastructure localization. The different resulting maps were combined in a final suitability map, which shows a high suitability area for the localization of multifunctional GI. The final map should be analyzed carefully in case it is used for actual policymaking and the participation of all stakeholders, decision-makers and involved population should be included.

The weighting process represents one of the most important steps of the process. It was done based on the literature review as well as on other similar case studies. Errors in relation to accuracy in the designated weights might occur. As variations in the weights assigned directly affect final results, prior to further studies, outcomes should be always checked and corrected by a group of experts, ensuring they correspond with the current situation and priorities sought. For this study, the identified areas recognized by the model were revised with the "Montevideo Resiliente" Strategy. As part of this strategy, a map was elaborated, locating the main impacts and tensions affecting the region, such as climate change impacts, ageing population, lack of social cohesion, inequity, poverty, housing issues, uncontrolled urban expansion, environmental degradation, infrastructure and inadequate transport systems [54]. In general, the intersection of high and very high suitability values (see Figure 6b) are within the spatial areas that the strategy recognizes as the area where the prioritized impacts and tensions are located and that need to be addressed.

Two important observations are drawn from the model and its results. Firstly, the model identifies potential areas for the implementation of GI as part of a region's masterplan (at the strategic level). The next step should be a deeper examination of those areas at a higher resolution (at a smaller scale) for example at the neighborhood level (operative level). Secondly, it is essential to determine appropriate and clear priority objectives so that accurate results can be achieved and the most quantity of possible benefits can be provided to the region, particularly during the final step (site level or implementation level).

Priority areas for GI implementation were determined. Previous to GI localization, a further step should be to ensure a finer scale analysis. This analysis should be done at the neighborhood level and should prioritize site locations to maximize the benefits of GI implementation. The evaluation needs to detect the most suitable locations to get the best results, according to the priorities and with the least economic costs. For the third level of analysis (implementation), further studies should include the needs and perception of different actors involved and local communities' participation.

\section{Conclusions}

The main purpose of the research, to develop a model to identify priority areas for GI localization in Montevideo, was achieved. Priority areas for the location of multifunctional GI were identified. These results contribute to future analysis on GI implementation in the region, especially for increasing its resilience and its capacity towards climate change adaptation.

The GISM can be adapted to changes in the context. The data and weights can be updated or substituted to respond to other challenges that the region may face in the future or to newly available information. Most significantly, the model developed can be adjusted to a different context. Therefore, the model developed is not limited to Montevideo and it can be extended to other regions.

Suitability analysis can play an important role as an effective decision tool in the policy-making process towards future driving forces such as climate change. The resultant suitability maps can be used as a tool to contribute to future plans or strategies for the development of the region. The areas rated as with high and very high suitability need to be studied at a closer level to be included in future plans for the development of GI in the region. If new green elements are implemented in connection with other existing green areas, they can become a network of GI that can help to restore natural ecosystems, support an increase of biodiversity and help to adapt the region to the impacts of climate change. In addition, it can provide ecological, social and economic benefits for the whole area. 
Author Contributions: Conceptualization, A.A., R.F., V.S. and D.M.; methodology, R.F. and V.S.; software, A.A; analysis, A.A., R.F., V.S. and D.M.; investigation, A.A., R.F., V.S. and D.M.; writing-original draft preparation, A.A.; writing-review and editing, R.F., V.S. and D.M; visualization, A.A.; supervision, R.F., V.S. and D.M. All authors have read and agreed to the published version of the manuscript.

Funding: This research was funded by the Agencia Nacional de Investigación e Innovación (ANII) from Uruguay, grant number [Res. $\mathrm{N}^{\circ}$ 2736-017] and The APC was funded by [Deakin University].

Acknowledgments: We would like to express our gratitude to Agencia Nacional de Investigación e Innovación (ANII) Uruguay, Universidad ORT Uruguay and Deakin University Australia.

Conflicts of Interest: The authors declare no conflict of interest.

\section{References}

1. United Nations Human Settlements Programme (UN-Habitat). World Cities Report 2016: Urbanization and Development-Emerging Futures; UN-Habitat: Nairobi, Kenya, 2016.

2. Organisation for Economic Co-operation and Development (OECD); European Commission. Cities in the World: A New Perspective on Urbanisation; OECD: Paris, French, 2020.

3. United Nations Environment Programme (UN Environment). Global Environment Outlook-GEO-6: Healthy Planet, Healthy People; UN Environment: Nairobi, Kenya, 2019.

4. Mostafavi, M.; Doherty, G. Ecological Urbanism; Revised Edition (2016); Switzerland Lars Müller Publishers: Zürich, Switzerland, 2016.

5. Liu, Z.; He, C.; Zhou, Y.; Wu, J. How much of the world's land has been urbanized, really? A hierarchical framework for avoiding confusion. Landsc. Ecol. 2014, 29, 763-771. [CrossRef]

6. Fragkias, M.; Lobo, J.; Strumsky, D.; Seto, K.C. Does size matter? Scaling of CO2 emissions and US urban areas. PLoS ONE 2013, 8, e64727. [CrossRef] [PubMed]

7. The Nature Conservancy. Nature in the Urban Century: A Global Assessment of Where and How to Conserve Nature for Biodiversity and Human Wellbeing; The Nature Conservancy: Arlington, MA, USA, 2018.

8. Smith, N.; Sinnett, D.; Burgess, S. Handbook on Green Infrastructure: Planning, Design and Implementation; Edward Elgar: Cheltenham, UK, 2015. [CrossRef]

9. Mantyka-Pringle, C.S.; Visconti, P.; Di Marco, M.; Martin, T.G.; Rondinini, C.; Rhodes, J.R. Climate change modifies risk of global biodiversity loss due to land-cover change. Biol. Conserv. 2015, 187, 103-111. [CrossRef]

10. Revi, A.; Satterthwaite, D.; Aragón-Durand, F.; Corfee-Morlot, J.; Kiunsi, R.; Pelling, M.; Roberts, D.; Solecki, W. Urban Areas in Climate Change 2014: Impacts, Adaptation, and Vulnerability. Part A: Global and Sectoral Aspects. Contribution of Working Group II to the Fifth Assessment Report of the Intergovernmental Panel on Climate Change; Cambridge University Press: Cambridge, UK; New York, NY, USA, 2014; pp. 535-612.

11. Douglas, I.A.; James, P. Urban Ecology: An Introduction; Routledge: New York, NY, USA, 2015.

12. Raymond, C.M.; Frantzeskaki, N.; Kabisch, N.; Berry, P.; Breil, M.; Nita, M.R.; Geneletti, D.; Calfapietra, C. A framework for assessing and implementing the co-benefits of nature-based solutions in urban areas. Environ. Sci. Policy 2017, 77, 15-24. [CrossRef]

13. Frumkin, H.; Bratman, G.N.; Breslow, S.J.; Cochran, B.; Kahn, P.H., Jr.; Lawler, J.J.; Levin, P.S.; Tandon, P.S.; Varanasi, U.; Wolf, K.L.; et al. Nature Contact and Human Health: A Research Agenda. Environ. Health Perspect 2017, 125, 075001. [CrossRef]

14. Bratman, G.N.; Anderson, C.B.; Berman, M.G.; Cochran, B.; de Vries, S.; Flanders, J.; Folke, C.; Frumkin, H.; Gross, J.J.; Hartig, T.; et al. Nature and mental health: An ecosystem service perspective. Sci. Adv. 2019, 5, eaax0903. [CrossRef]

15. Andersson, E.; Haase, D.; Scheuer, S.; Wellmann, T. Neighbourhood character affects the spatial extent and magnitude of the functional footprint of urban green infrastructure. Landsc. Ecol. 2020, 35, 1605-1618. [CrossRef]

16. Mell, I. Green Infrastructure: Concepts, Perceptions and Its Use in Spatial Planning. Thesis Submitted for the Degree of Doctor of Philosophy. Ph.D. Thesis, School of Architecture, Planning and Landscape, Newcastle University, England, UK, 2010.

17. Ramyar, R.; Zarghami, E. Green infrastructure contribution for climate change adaptation in urban landscape context. Appl. Ecol. Environ. Res. 2017, 15, 1193-1209. [CrossRef] 
18. Mell, I. Green infrastructure: Reflections on past, present and future praxis. Landsc. Res. 2017, 42, 135-145. [CrossRef]

19. Pauleit, S.; Liu, L.; Ahern, J.; Kazmierczak, A. Multifunctional Green Infrastructure Planning to Promote Ecological Services in the City. In Handbook of Urban Ecology; Oxford University Press: Oxford, UK, 2011; pp. 272-285. [CrossRef]

20. Vásquez, A.; Galdámez, E.; Jara, R.; Navarro, V. Infraestructura Verde en Uruguay: Desafíos y Oportunidades; BID: Santiago, Chile, 2017.

21. Intendencia de Montevideo (IM); 100 Resilient Cities. Montevideo Resiliente, Evaluación Preliminar de Resiliencia; IM: Montevideo, Uruguay, 2018.

22. Ministerio de Vivienda Ordenamiento Territorial y Medio Ambiente (MVOTMA). Plan Nacional de Adaptación de Ciudades e Infraestructuras, Sintesis de Nap Ciudades, Complete Document; MVOTMA: Montevideo, Uruguay, 2018.

23. Benedict, M.; McMahon, E. Green Infrastructure: Linking Landscapes and Communities; Island Press: Washington, WA, USA, 2006.

24. Hansen, R.; Rall, E.; Chapman, E.; Rolf, W.; Pauleit, S. Urban Green Infrastructure Planning: A Guide for Practitioners. 2017. Available online: https://www.researchgate.net/publication/319967102_Urban_Green_ Infrastructure_Planning_A_Guide_for_Practitioners (accessed on 30 July 2019).

25. Hansen, R.; Pauleit, S. From Multifunctionality to Multiple Ecosystem Services? A Conceptual Framework for Multifunctionality in Green Infrastructure Planning for Urban Areas. AMBIO 2014, 43, 516-529. [CrossRef]

26. Pickett, S.T.A.; Cadenasso, M.L.; Grove, J.M.; Boone, C.G.; Groffman, P.M.; Irwin, E.; Kaushal, S.S.; Marshall, V.; McGrath, B.P.; Nilon, C.H.; et al. Urban ecological systems: Scientific foundations and a decade of progress. J. Environ. Manag. 2011, 92, 331-362. [CrossRef] [PubMed]

27. Biggs, R.; Rhode, C.; Archibald, S.; Kunene, L.M.; Mutanga, S.S.; Nkuna, N.; Ocholla, P.O.; Phadima, L.J. Strategies for managing complex social-ecological systems in the face of uncertainty: Examples from South Africa and beyond. Ecol. Soc. 2015, 20, 52. [CrossRef]

28. Jones, S.; Somper, C. The role of green infrastructure in climate change adaptation in London. Geogr. J. 2014, 180, 191-196. [CrossRef]

29. Staddon, C.; Ward, S.; De Vito, L.; Zuniga-Teran, A.; Gerlak, A.K.; Schoeman, Y.; Hart, A.; Booth, G. Contributions of green infrastructure to enhancing urban resilience. Environ. Syst. Decis. 2018, 38, 330-338. [CrossRef]

30. European Commission. Towards an EU Research and Innovation policy agenda for Nature-Based Solutions $\mathcal{E}$ Re-Naturing Cities. Final Report of the Horizon 2020 Expert Group on 'Nature-Based Solutions and Re-Naturing Cities'; European Commission: Brussels, Belgium, 2015. [CrossRef]

31. Madureira, H.; Andresen, T. Planning for multifunctional urban green infrastructures: Promises and challenges. Urban Des. Int. 2014, 19, 38-49. [CrossRef]

32. Meerow, S.; Newell, J. Spatial planning for multifunctional green infrastructure: Growing resilience in Detroit. Landsc. Urban Plan. 2017, 159, 62-75. [CrossRef]

33. Instituto Nacional de Estadística (INE). Instituto Nacional de Estadística Uruguay. Available online: http://www.ine.gub.uy/ (accessed on 30 July 2019).

34. Intendencia de Montevideo(IM). Estrategia de Resiliencia, Montevideo Resiliente; Unidad Ejecutiva de Resiliencia, IM: Montevideo, Uruguay, 2018.

35. Intendencia de Montevideo (IM). Directrices Departamentales de Ordenamiento Territorial y Desarrollo Sostenible; IM: Montevideo, Uruguay, 2012.

36. Ministerio de Vivienda Ordenamiento Territorial y Medio Ambiente (MVOTMA); Plan Nacional de Adaptación al Cambio Climático en Ciudades e Infraestructuras (NAP Ciudades). Cambia el Clima, Cambiemos Nosotros/as. Breve Guía Para Entender el Cambio Climático; MVOTMA: Montevideo, Uruguay, 2019.

37. Intendencia de Montevideo (IM). Medidas de Resiliencia para Montevideo, Inundaciones y Saneamiento, División Saneamiento; Servicios de Estudio y Proyectos de Saneamiento (SEPS-IM): Montevideo, Uruguay, 2017.

38. Piperno, A.; Sierra, P. Inundaciones en el Uruguay: Aportes desde el Ordenamiento Territorial; Instituto de Teoría de la Arquitectura y Urbanismo (ITU), Facultad de Arquitectura (FARQ), Universidad de la República (Udelar): Montevideo, Uruguay, 2010.

39. Collins, M.G.; Steiner, F.R.; Rushman, M.J. Land-Use Suitability Analysis in the United States: Historical Development and Promising Technological Achievements. Environ. Manag. 2001, 28, 611-621. [CrossRef] 
40. Voogd, H. Multicriteria Evaluation for Urban and Regional Planning; Pion: London, UK, 1983.

41. Keeney, R.L.; Raiffa, H. Decisions with Multiple Objectives: Preferences and Value Trade-Offs; Cambridge University Press: Cambridge, UK, 1976. [CrossRef]

42. Carver, S.J. Integrating multi-criteria evaluation with geographical information systems. Int. J. Geogr. Inf. Syst. 1991, 5, 321-339. [CrossRef]

43. Jankowski, P.; Richard, L. Integration of GIS-based suitability analysis and multicriteria evaluation in a spatial decision support system for route selection. Environ. Plan. B Plan. Des. 1994, 21, 323-340. [CrossRef]

44. Thapa, R.B.; Murayama, Y. Land evaluation for peri-urban agriculture using analytical hierarchical process and geographic information system techniques: A case study of Hanoi. Land Use Policy 2008, 25, 225-239. [CrossRef]

45. Cengiz, T.; Akbulak, C. Application of analytical hierarchy process and geographic information systems in land-use suitability evaluation: A case study of Dümrek village (Çanakkale, Turkey). Int. J. Sustain. Dev. World Ecol. 2009, 16, 286-294. [CrossRef]

46. McHarg, I.L. Design with Nature; Published for the American Museum of Natural History [by] the Natural History Press: Garden City, NY, USA, 1969.

47. Spósito, V. Strategic Thinking, Strategic Planning and Decision Making; Centre for Regional and Rural Futures, Faculty of Science, Engineering and Built Environment, Deakin University: Victoria, Australia, 2018.

48. Norton, B.A.; Coutts, A.M.; Livesley, S.J.; Harris, R.J.; Hunter, A.M.; Williams, N.S.G. Planning for cooler cities: A framework to prioritise green infrastructure to mitigate high temperatures in urban landscapes. Landsc. Urban Plan. 2015, 134, 127-138. [CrossRef]

49. Saaty, T.L.; De Paola, P. Rethinking Design and Urban Planning for the Cities of the Future. Buildings 2017, 7, 76. [CrossRef]

50. Saaty, T.L. Decision Making for Leaders: The Analytic Hierarchy Process for Decisions in a Complex World; RWS Publications: Pittsburgh, PA, USA, 1995.

51. Bantayan, N.C.; Bishop, I.D. Linking objective and subjective modelling for landuse decision-making. Landsc. Urban Plan. 1998, 43, 35-48. [CrossRef]

52. Goepel, K.D.; AHP Analytic Hierarchy Process (EVM multiple inputs). Version 04.05.2016. Free web based AHP software. Available online: https://bpmsg.com/ (accessed on 30 July 2019).

53. ESRI ArcMap GIS 10.5.1. Computer Software; Environmental Systems Research Institute, Inc.: Redlands, CA, USA, 2017.

54. Intendencia de Montevideo (IM); 100 Resilient Cities; ARUP. Reporte Final Taller de Lanzamiento Montevideo Resiliente; IM: Montevideo, Uruguay, 2019.

Publisher's Note: MDPI stays neutral with regard to jurisdictional claims in published maps and institutional affiliations.

(C) 2020 by the authors. Licensee MDPI, Basel, Switzerland. This article is an open access article distributed under the terms and conditions of the Creative Commons Attribution (CC BY) license (http://creativecommons.org/licenses/by/4.0/). 